\title{
ANALISIS DATA LIFTING MIGAS MENGGUNAKAN METODE C4.5 PADA ASOSIASI DAERAH PENGHASIL MIGAS
}

\author{
Ahmad Husain \\ Program Studi Informatika, Universitas Indraprasta PGRI \\ hnr.husen@Gmail.com
}

\begin{abstract}
Abstrak
Salah satu program Kerja ADPM setiap tahun adalah memberikan analisis data lifting migas kepada seluruh anggota ADPM. Tujuan diadakan penelitian ini adalah membuat pihak daerah penghasil migas dapat mengambil keputusan dalam menentukan penerimaan daerah dari penjualan minyak bumi dan gas secara tepat dan dengan waktu seefisien mungkin. Dalam proses pembuatan pengambilan keputusan dibutuhkan data mentah yang akan diolah sehingga akan menghasilkan suatu keputusan yang tepat. Langkah awal yang harus dilakukan yaitu memasukkan data anggota daerah penghasil, data produksi nya maupun data lifting migas tahun 2014-2015 dengan menggunakan Microsoft Excel yang nantinya akan dijadikan sebagai data mentah dalam aplikasi pengolahan data RapidMiner. Langkah kedua yaitu menyeleksi data-data yang tidak diperlukan dalam proses pengolahan data di RapidMiner. Dari data yang telah diseleksi inilah yang akan dijadikan data training, data training tersebut akan dibuat beberapa klasifikasi yang diperlukan agar dalam proses pengelolaan data mendapatkan hasil yang akurat dan tepat, sehingga Daerah Penghasil Migas dapat menentukan realisasi lifting dengan tepat dan akurat.
\end{abstract}

Kata Kunci: Analisis Data Lifting Migas, Algoritma C45, Data mining

\begin{abstract}
One of ADPM's Work programs every year is to provide a data analysis of oil and gas lifting to all members of ADPM. The purpose of this research is to make the regional oil and gas producers can take decisions in determining the regional revenue from the sale of oil and gas in a timely and efficient manner. In the process of making decision-making required raw data to be processed so that will produce an appropriate decision. The first step that must be done is entering data member of producing region, its production data and data of oil and gas lifting year 2014-2015 by using Microsoft Excel which will be used as raw data in RapidMiner data processing application. The second step is selecting data that is not needed in data processing in RapidMiner. From the data that has been selected that will be used as training data, training data will be made some classification required for the process of data management to get accurate and precise results, so that the Region Oil and Gas Producers can determine the realization of lifting with precise and accurate.
\end{abstract}

Keywords: Oil Data Lifting Analysis, C45 Algorithm, Data mining

\section{PENDAHULUAN}

Asosiasi Daerah Penghasil Migas (ADPM) adalah organisasi yang beranggotakan 89 daerah penghasil migas seluruh Indonesia yang terdiri dari beberapa provinsi, kabupaten dan kota, salah satu program Kerja ADPM setiap tahun adalah memberikan analisis data lifting migas kepada seluruh anggota ADPM. Kajian ini meliputi angka - angka lifting dari tahun ke tahun dan pembagian dana bagi hasil ke daerah. Hal ini penting karena angka lifting adalah angka sebagai perhitungan dasar dalam membagi penerimaan Negara bukan pajak.

Dari angka Lifting yang diberikan dapat diketahui berapa besar Pendapatan Kotor (Gross Revenue) yang akan diperoleh dari suatu Kontraktor di Daerah Penghasil, yang kemudian oleh Ditjen Migas akan 
ditentukan berapa besar Lifting Pemerintah yang akan diperoleh Negara.

Tentu saja kajian ini masih bersifat mendasar dan perlu kajian yang lebih dalam mengenai mengapa suatu lifting ditempat ini turun atau mengalami kenaikan begitu juga dengan angka bagi hasil migas di daerah. Semoga dengan informasi kajian ini dapat memberikan suatu gambaran umum yang akan di dapat daerah dalam tahun anggaran berjalan, sehingga dapat mewaspadai produksi lifting dan pendapatan bagi hasil kita yang masih sering diluar dugaan, sehingga dapat diprediksi dengan tepat.

\section{Data Mining}

Data mining merupakan serangkaian proses untuk menggali nilai tambah berupa informasi yang selama ini tidak diketahui secara manual dari suatu basis data atau bisa disebut dengan KDD ( Knowledge Discovery in Database). Dimana definisi KDD adalah proses non-trivial untuk mengidentifikasi pola dari data yang valid, baru, berpotensi menjadi pengetahuan yang bermanfaat dan dapat dimengerti. Menurut [1]. Data mining adalah penemuan pengetahuan dangan menggunakan teknik-teknik yang tergabung dari statistik, tradisional, kecerdasan buatan (artificial intelligence) dan grafik komputer. Data mining merupakan proses ektraksi pengetahuan dari data yang besar. Sesuai fungsinya, menurut [2]. Data mining adalah proses pencarian pola data yang tidak diketahui atau tidak diperkirakan sebelumnya. Sedangkan menurut [3]. Data mining adalah kegiatan mengeksplorasi dan menganalisis data jumlah yang besar untuk menemukan pola (pattern) dan aturan (rule) yang berarti.

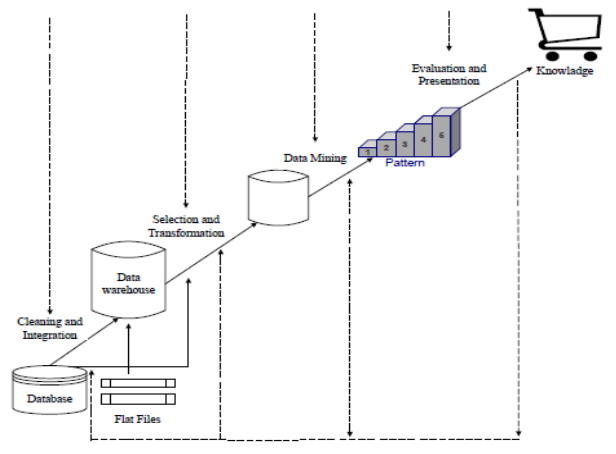

Gambar 1. Proses Knowledge Discovery in Databases (KDD)

\section{Algoritma C4.5}

a. Konsep Algoritma C4.5

Algoritma merupakan kumpulan perintah yang tertulis secara sistematis guna menyelesaikan permasalahan logika dari matematika. Pengertian Algoritma C4.5 merupakan algoritma yang digunakan untuk membentuk pohon keputusan. Gambar berikut ini.

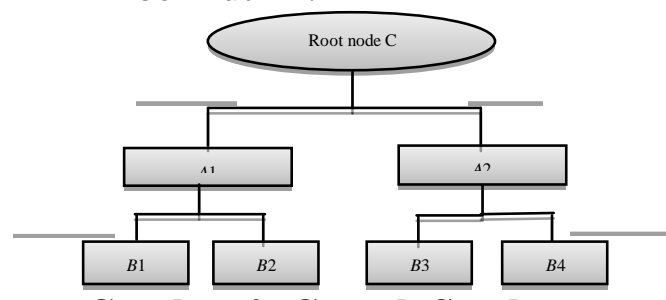

Gambar 2. Contoh Struktur

Decision Tree

b. Algoritma Klasifikasi Data Mining Klasifikasi dalam data mining merupakan metode pembelajaran data untuk memprediksi nilai dari sekelompok attribut. Menurut [4] Algoritma klasifikasi akan menghasilkan sekumpulan aturan yang disebut rule yang akan digunakan sebagai indikator untuk dapat memprediksi kelas dari data yang ingin diprediksi. 


\section{LIFTING MIGAS}

Lifting migas adalah produksi migas yang siap jual. Besaran lifting ini bisa berbeda dengan besaran produksi karena tidak semua produksi migas yang baru keluar dari dalam bumi bisa langsung dijual. Dalam beberapa kasus, produksi migas masih harus diproses atau diangkut sebelum menjadi lifting. Istilah lifting juga kerap dipakai untuk menggambarkan proses penyerahan migas dari produsen kepada pembeli. Pada proses inilah penerimaan negara dari kegiatan hulu migas terealisasi.

\section{PHP}

Menurut [5], PHP memiliki beberapa pandangan dalam mengartikannya, akan tetapi kurang lebih PHP dapat kita ambil arti sebagai PHP : Hypertext Preeprocesor. Ini merupakan bahasa yang hanya dapat berjalan pada server dan hasilnya dapat di tampilkan pada client.

\section{MySQL}

Menurut [6] MySQL merupakan sebuah perangkat lunak sistem manajemen basis data atau DBMS yang multiuser, dengan sekitar 6 juta instalasi diseluruh dunia. Karena sifatnya yang open source dan memiliki kemampuan menampung kapasitas yang sangat besar, maka MySQL menjadi database yang sangat popular dikalangan programmer web. Menurut [7], MySQL merupakan software yang tergolong sebagai DBMS (database Management System) yang bersifat open source. Open source menyatakan bahwa software ini dilengkapi dengan source code (kode yang dipakai untuk membuat MySQL). Selain itu tentu saja bentuk executable-nya atau kode yang dapat dijalankan secara langsung dalam sistem operasi dan bisa diperoleh secara gratis dengan mendownload di internet.

\section{XАMPP}

XAMPP merupakan paket PHP yang berbasis open source yang dikembangkan oleh sebuah komunitas open source. Dengan menggunakan XAMPP tidak dibingungkan dengan penginstalan program-program lain, karena semua kebutuhan terlah tersedia oleh XAMPP. Yang terdapat pada XAMPP di antaranya : Apache, MySQL, PHP, FileZilla FTP Server, PHPmyAdmin dll.

\section{Notepad++}

Notepad adalah Program bawaan dari Windows yang biasa digunakan untuk menulis keterangan-keterangan yang penting dari program aplikasi seperti halnya lisensi program atau yang lainnya.

\section{RapidMiner}

RapidMiner merupakan software untuk pengolahan data mining. RapidMiner Sebuah lingkungan untuk machine learning, data mining, text mining dan predictive analytics. Machine learning Algoritma dimana perilaku komputer berevolusi berdasarkan data empiris, seperti sensor atau database. Data mining proses mengekstrak pola-pola dari data set yang besar dengan mengkombinasikan metode statistika, kecerdasan buatan dan database.

\section{2 . METODE PENELITIAN}

Metode yang digunakan dalam penelitian ini yaitu metode experimental. penelitian terdiri dari mendefinisikan dan mendefinisikan ulang masalah, merumuskan hipotesa atau menyarankan solusi, mengumpulkan, mengorganir dan mengevaluasi data, membuat deduksi dan mencapai kesimpulan, dan berakhir pada menguji kesimpulan untuk menentukan apakah hasil dari penelitian tersebut sesuai dengan rumusan hipotesa..

Kegiatan penelitian ini melalui beberapa tahap dalam pengembangannya yaitu :

1. Data

2. Pengolah Data 


\section{Laporan}

\section{Metode Pengumpulan Data}

\section{Data Primer}

Data primer merupakan data instrument dari penelitian. Data primer merupakan data yang diperoleh secara langsung dari nara sumber baik dari wawancara maupun observasi.

2. Data Sekunder

Data sekunder merupakan data yang diperoleh secara tidak langsung. Data sekunder dari penelitian ini diperoleh dari website.

\section{Langkah-langkah Pengembangan}

Sistem.

Pada tahap pengembangan sistem penentuan Analisis data lifting migas, penulis menggunakan metode waterfall. Waterfall adalah sebuah model perkembangan perangkat lunak dilakukan secara sekuensial, dimana satu tahap dilakukan setelah tahap sebelumnya selesai dilaksanakan. Model waterfall ini mengambil kegiatan dasar seperti spesifikasi persyaratan, perancangan perangkat lunak, implementasi, pengujian, dan seterusnya.

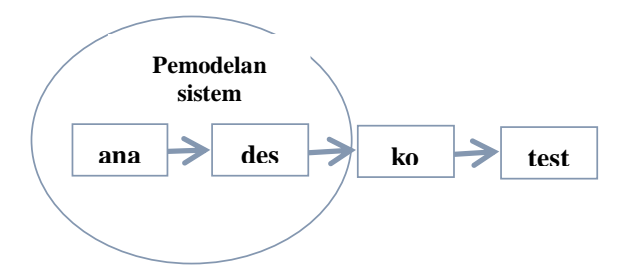

\section{Gambar 3. Model waterfall menurut Roger S. Pressman}

\section{HASIL DAN PEMBAHASAN \\ Definisi Masalah}

Masalah yang dihadapi dalam sistem yang ada pada anggota daerah penghasil, yaitu bagaimana pihak daerah penghasil migas dapat mengambil keputusan dalam menentukan penerimaan daerah dari penjualan minyak bumi dan gas secara tepat dan dengan waktu seefisien mungkin. Dalam proses pembuatan pengambilan keputusan dibutuhkan data mentah yang akan diolah sehingga akan menghasilkan suatu keputusan yang tepat.
a. Identifikasi Masalah
b. Konseptualisasi Masalah

\section{Penyelesaian}

Dari masalah yang telah dijelaskan sebelumnya, maka penyelesaian yang dapat dilakukan untuk mencari solusi dari masalah tersebut yaitu dengan mengolah data menggunakan aplikasi pengolah data RapidMiner, Dari pohon keputusan dan rule tersebut, maka dapat terlihat proses kerja yang dilakukan RapidMiner hingga menghasilkan suatu keputusan. Berikut ini adalah rule yang dihasilkan dari data lifting migas yang telah diolah :

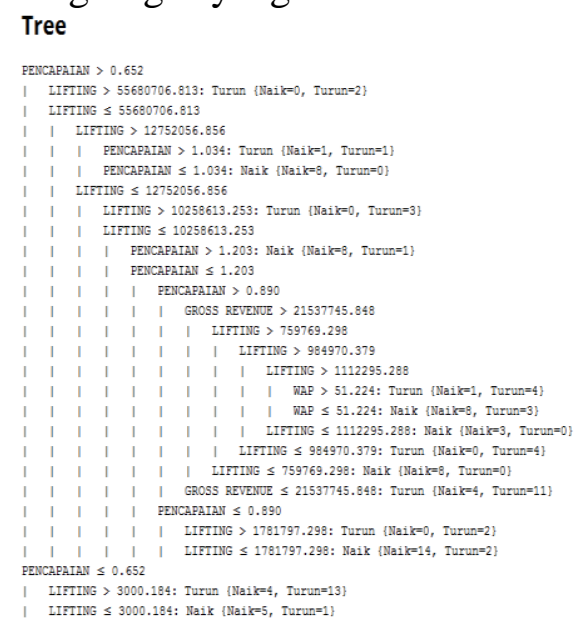

Gambar 4. Rule yang dihasilkan

\section{A. Algoritma Penyelesaian masalah dengan algoritma Flowchart dan Pseudocode}

Algoritma berisi deskripsi langkahlangkah pemecahan masalah. Langkah langkah pemecahan masalah tesebut dapat dituliskan dalam notasi algoritmik sembarang. Notasi algoritmik yang baik adalah notasi yang mudah dibaca dan ditranslasikan ke dalam notasi bahasa pemrograman. Notasi algoritmik berupa pseudocode mempunyai korespondensi dengan notasi bahasa pemrograman sehingga proses penerjemah dari pseudocode ke kode program menjadi lebih mudah. 
Flowchart klasifikasi penentuan Analisis Lifting Migas adalah sebagai berikut :

1. Flowchart Sistem :

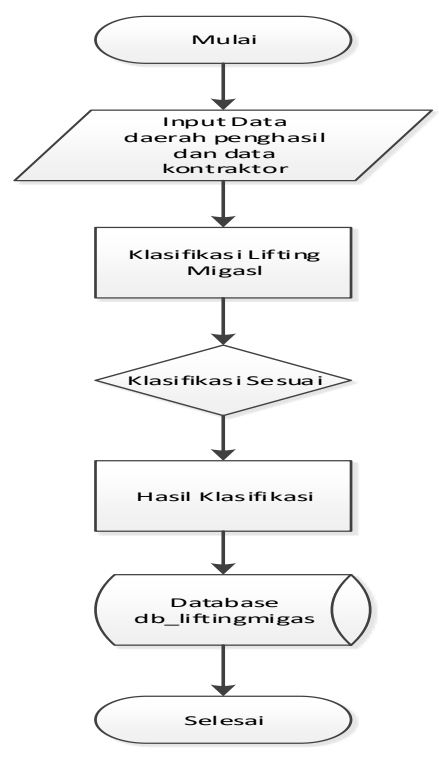

Gambar 5. Flowchart Sistem.

2. Modul Aplikasi Analisis Lifting Migas :

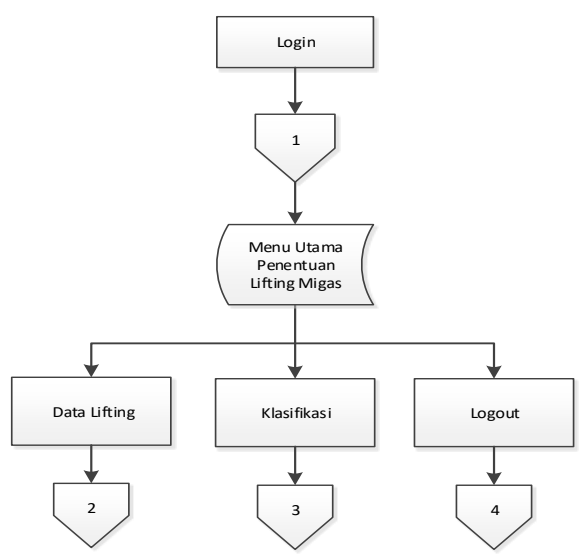

Gambar 6. Modul Aplikasi Analisis Lifting Migas
3. Flowchart Modul 1, Menu Login dan Pseudocodenya

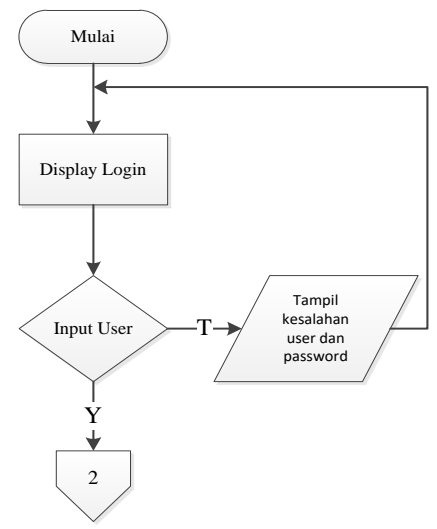

Gambar 7. Flowchart Menu Login

4. Flowchart Modul 2, Menu Form Data Lifting Migas dan Pseudocodenya :

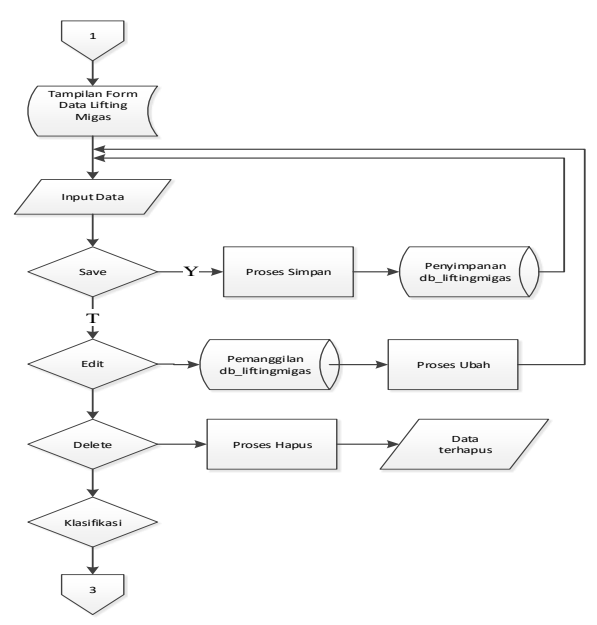

Gambar 8. Flowchart Menu Form Data Lifting Migas. 
5. Flowchart Modul 3, Menu Klasifikasi dan Pseudocodenya :

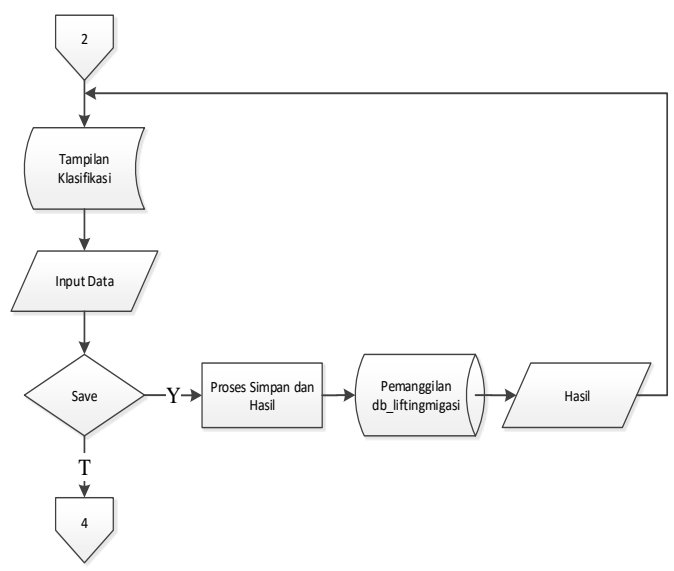

\section{Gambar 9. Flowchart Menu Klasifikasi}

Setelah user selesai menginput data daerah penghasil migas dan Kontraktor pada form data lifting migas, selanjutnya user dapat menginput data nilai pada menu klasifikasi. Setelah itu pilih "Save" untuk mendapatkan hasil dari klasifikasi lifting migas dan otomatis akan tersimpan pada database db_liftingmigas. Jika tidak maka ke modul 4.

\section{Flowchart Modul 4, Menu Logout dan Pseudocodenya}

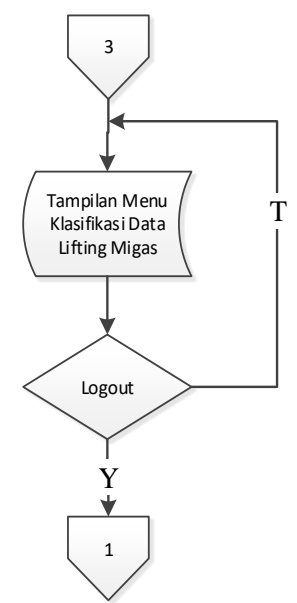

Gambar 10. Flowchart Menu Logout
Setelah proses Klasifikasi Data Lifting Migas selesai atau user ingin keluar dari Aplikasi ini, user dapat memilih menu Logout. Jika tidak maka kembali ke tampilan Klasifikasi Data Lifting Migas.

\section{B. Pembahasan Algoritma}

Pembahasan algoritma pada aplikasi penentuan Analisis Lifting Migas Pada Asosiasi Daerah Penghasil Migas yaitu :

1. Algoritma Menu Login

a. Menu Login Dilakukan oleh user (admin) saja.

b. Setelah tampil menu Login, input username dan password dengan benar sesuai dengan user yang telah ditentukan.

c. Jika username dan password sudah benar, maka user berhak masuk ke dalam menu utama yang telah disediakan pada aplikasi ini.

2. Algoritma tampilan menu form data Lifting Migas

a. Menu form data lifting migas merupakan tampilan awal setelah melakukan login, menu ini berisi form data daerah penghasil migas dan kontraktor yang harus diinput oleh user.

b. Setelah form data lifting terinput maka data akan tersimpan ke dalam database.

3. Algoritma tampilan menu klasifikasi

a. Menu klasifikasi merupakan menu yang berisi form nilai. Sebelum mengisi form nilai user harus memasukkan nilai lifting daerah penghasil migas. Setelah selesai menginput, data 
akan tersimpan ke dalam database dan menghasilkan sebuah keterangan hasil dari klasifikasi tersebut.

b. Di dalam menu klasifikasi ini user dapat melihat data lifting daerah penghasil migas yang naik dan data lifting daerah penghasil migas yang turun secara terpisah karena terdapat dua button yaitu "lifting migas yang naik" dan "lifting migas yang turun". Jika pilih "lifting migas yang naik" maka akan muncul tabel berisi data lifting yang naik dan jika pilih "lifting migas yang turun" maka akan muncul tabel berisi lifting migas yang turun.

c. Jika ingin keluar dari aplikasi ini, user dapat memilih logout pada menu pengaturan user.

\section{Uji Coba Program dengan Contoh Data}

Dalam menjalankan program yang dibuat ini maka diperlukan perangkat nyata seperti Laptop atau PC. Untuk melihat uji coba dari program ini diperlukan perangkat lunak pendukung yang akan menjadi media untuk menjalanakan sistem yaitu Notepad ++ sebagai media menulis kode program, pengembangan dan pengujian sistem database server MySQL sebagai koneksi dan penyimpanan data lifting migas. Database server ini telah terhubung dalam satu paket Xampp Versi 5.6.30, Windows 10 Pro 64bit Tahun 2015.
1. Tampilan database

Langkah pertama yang dilakukan untuk menjalankan atau mengkoneksikan sistem yakni dengan memastikan bahwa perangkat lunak Xampp versi 5.6.30, Windows 10 Pro 64bit dalam kondisi berjalan (running) dengan cara klik logo windows - All Program folder Xampp - Xampp Control Panel, Selanjutnya klik tombol start pada bagian Apache dan MySQL hingga muncul warna hijau pada tulisan Apache dan MySQL.

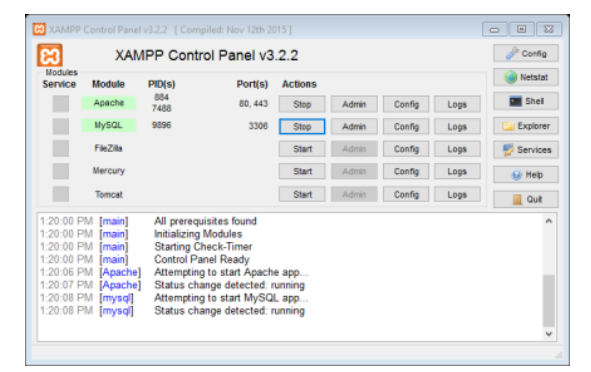

\section{Gambar 11. Xamppp Control Panel}

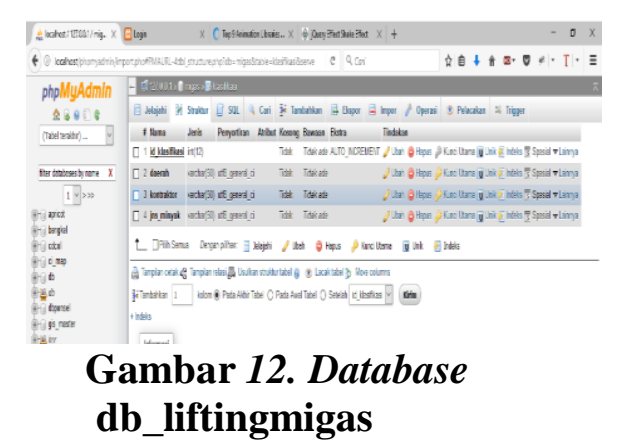

2. Tampilan Menu Login

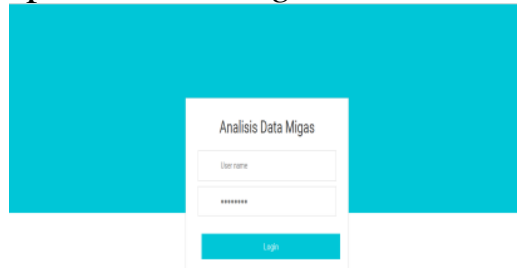

Gambar 13. Menu Login 
3. Tampilan Menu Utama

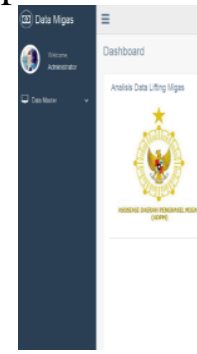

Gambar 14. Menu Utama

4. Tampilan Menu Form Data lifting migas

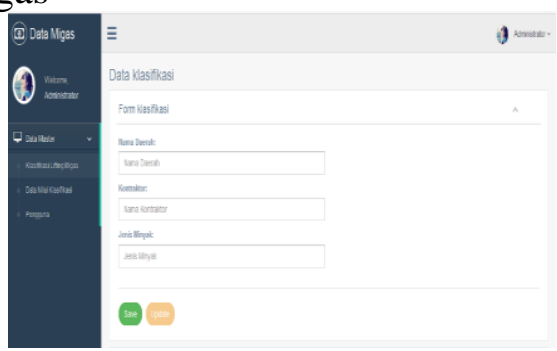

\section{Gambar 15. Menu Form Data lifting migas}

5. Tampilan Menu Klasifikasi

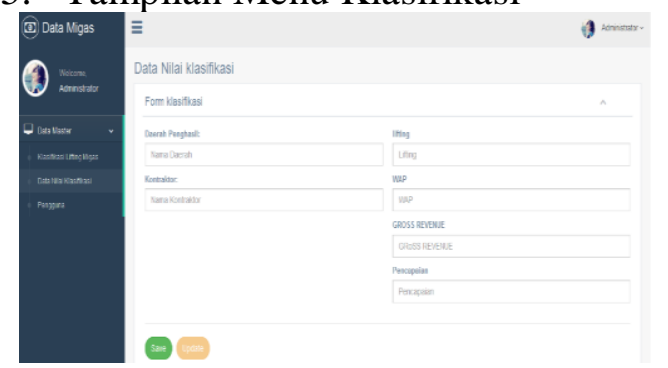

Gambar 16. Menu Klasifikasi

D. Pembahasan Hasil Uji Coba

Metode yang digunakan dalam pembuatan aplikasi klasifikasi penentuan Analisis Lifting Migas adalah Algoritma C4.5. Algoritma C4.5 yaitu Pohon keputusan yang merupakan metode klasifikasi dan prediksi yang sangat kuat dan terkenal. Metode pohon keputusan mengubah fakta yang sangat besar menjadi pohon keputusan yang merepresentasikan aturan. Aturan tersebut dapat dengan mudah dipahami dengan bahasa alami. Dengan menggunakan klasifikasi algoritma C.4.5 dalam menentukan Analisis Lifting Migas, terbentuklah sebuah pohon keputusan (decision tree) yang didapat dalam pengolahan data menggunakan aplikasi RapidMiner.

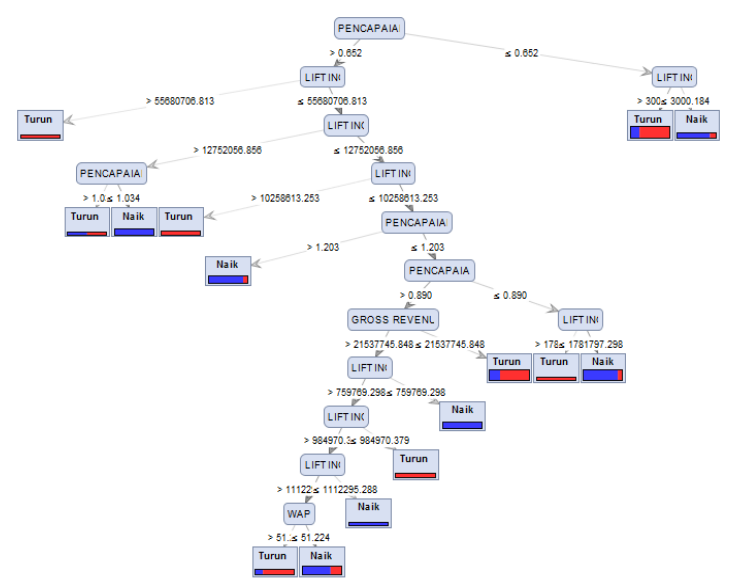

Gambar 17. Pohon Keputusan (Decision Tree)

Dari gambar pohon keputusan diatas, maka didapatkan sebuah aturan (rule) yang menjadi acuan dalam pembuatan aplikasi dengan menggunakan bahasa pemrograman PHP adalah sebagai berikut :

1. R1 : IF Pencapaian $\leq 0.652$ AND

Lifting $>3000.184=$ Turun

2. R2 : IF Pencapaian $\leq 0.652$ AND

Lifting $\leq 3000.184=$ Naik

3. L1 : IF Pencapaian > 0.652 AND

Lifting $>55680706.813=$ Turun

4. L2 : IF Pencapaian > 0.652 AND

Lifting $\leq 55680706.813$ ELSE IF

Lifting > 12752056.856 AND

Pencapaian $>1.034=$ Turun

5. L3 : IF Pencapaian > 0.652 AND

Lifting $\leq 55680706.813$ ELSE IF

Lifting > 12752056.856 AND

Pencapaian $\leq 1.034=$ Naik 
6. L4 : IF Pencapaian > 0.652 AND Lifting $\leq 12752056.856$ THEN ELSE Lifting > 10258613.253 = Turun

7. L5 : IF Pencapaian > 0.652 AND Lifting $\leq 12752056.856$ THEN ELSE Lifting $\leq 10258613.253$ $A N D$ Pencapaian $>1.203=$ Naik

8. LR1 : IF Pencapaian $>0.652$ AND Lifting $\leq 12752056.856$ THEN ELSE Lifting $\leq 10258613.253$ $A N D$ Pencapaian $\leq 0.890$ AND Lifting $>1781797.298=$ Turun

9. LR2 : IF Pencapaian >0.652 AND Lifting $\leq 12752056.856$ THEN ELSE Lifting $\leq 10258613.253$ $A N D$ Pencapaian $\leq 0.890$ AND Lifting $\leq 1781797.298=$ Naik

10. L6 : IF Pencapaian > 0.652 AND Lifting $\leq 12752056.856$ THEN ELSE Lifting $\leq 10258613.253$ $A N D$ Pencapaian $\leq 1.203$ AND IF Pencapaian > 0.890 THEN Gross Revenue $\leq 21537745.848=$ Turun

11. L7 : IF Pencapaian > 0.652 AND Lifting $\leq 12752056.856$ THEN ELSE Lifting $\leq 10258613.253$ $A N D$ Pencapaian $\leq 1.203$ AND IF Pencapaian > 0.890 AND Gross Revenue > 21537745.848 AND IF Lifting $\leq 759769.298=$ Naik

12. L8 : IF Pencapaian $>0.652$ AND Lifting $\leq 12752056.856$ THEN ELSE Lifting $\leq 10258613.253$ AND Pencapaian $\leq 1.203$ AND IF Pencapaian > 0.890 AND Gross Revenue > 21537745.848 AND IF Lifting > 759769.298 AND IF Lifting $\leq 984970.379=$ Turun

13. L9 : IF Pencapaian $>0.652$ AND Lifting $\leq 12752056.856$ THEN ELSE Lifting $\leq 10258613.253$ $A N D$ Pencapaian $\leq 1.203$ AND IF Pencapaian > 0.890 AND Gross Revenue > 21537745.848 AND IF Lifting > 759769.298 AND IF
Lifting > 984970.379 AND IF Lifting $\leq 1112295.288=$ Naik

14. L9 : IF Pencapaian > 0.652 AND Lifting $\leq 12752056.856$ THEN ELSE Lifting $\leq 10258613.253$ AND Pencapaian $\leq 1.203$ AND IF Pencapaian > 0.890 AND Gross Revenue > 21537745.848 AND IF Lifting > 759769.298 AND IF Lifting > 984970.379 AND IF Lifting > 1112295.288 AND WAP $\leq 51.224=$ Naik

15. L9 : IF Pencapaian > 0.652 AND Lifting $\leq 12752056.856$ THEN ELSE Lifting $\leq 10258613.253$ $A N D$ Pencapaian $\leq 1.203$ AND IF Pencapaian > 0.890 AND Gross Revenue > 21537745.848 AND IF Lifting > 759769.298 AND IF Lifting > 984970.379 AND IF Lifting > 1112295.288 AND WAP $>51.224=$ Turun

Pada tabel 1 merupakan perhitungan akurasi dari data training menggunakan algoritma C45. Diketahui data training terdiri dari 111 record data, 39 data diklasifikasikan Naik dan 26 data diprediksikan Naik ternyata Turun, 25 data dinyatakan Turun tetapi Naik dan 21 data secara benar diklasifikasikan turun.

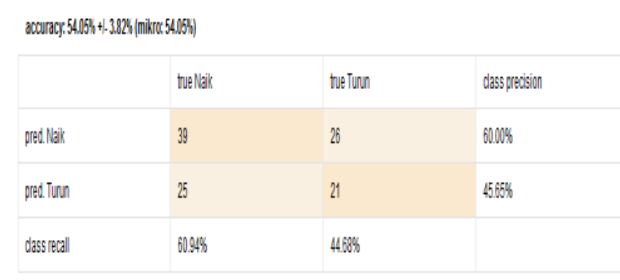

\section{Gambar 18. Hasil Akurasi}

\section{E. Penjelasan tentang Kelebihan dan Kelemahan Sistem}

Aplikasi Penentuan Analisis Lifting Migas pada Asosiasi Daerah Penghasil Migas yang peneliti buat, masih memiliki kekurangan. Berikut adalah kelemahan dan kelebihan dari Aplikasi Penentuan Analisis 
Lifting Migas Pada Asosiasi Daerah Penghasil Migas yaitu :

1. Kelebihan

a. Sistem aplikasi ini dapat digunakan oleh pihak lain untuk penentuan analisis.

b. Tampilan yang sederhana dan mudah dipahami oleh pengguna (user).

c. Aplikasi ini dapat membantu pihak Anggota Daerah Penghasil Migas untuk penentuan analisis lifting migas dengan cepat, tepat dan akurat. oleh sembarang orang.

2. Kelemahan

a. Hasil dari klasifikasi ini tidak bisa dilihat langsung oleh Anggota Daerah Penghasil Migas.

b. Tampilan yang masih sangat sederhana dan belum optimal.

c. Hanya dapat digunakan diperangkat Personal Control (PC) dan Laptop saja.

d. Tidak Bisa digunakan oleh pihak lain untuk penentuan analisis dengan kriteria yang berbeda.

\section{Simpulan}

\section{SIMPULAN}

Sesuai dengan hasil penelitian dan pembahasan mengenai sistem analisis lifting migas dapat dikemukakan beberapa simpulan sebagai berikut :

1. Sistem aplikasi penentuan analisis lifting migas dengan menggunakan metode Algoritma C4.5 ini dapat digunakan oleh staff admin Asosiasi Daerah Penghasil Migas dalam proses penentuan analisis lifting migas agar penentuan analisis lifting menjadi lebih optimal.

2. Aplikasi ini bertujuan untuk menghasilkan keputusan yang optimal, tepat dan akurat dalam melakukan analisis lifting migas menggunakan d. Aplikasi ini tidak dapat digunakan

metode Algoritma $C 45$ berdasarkan empat kriteria sebagai berikut :
a. Jenis Minyak.
b. Data Lifting tahun 2014 dan 2015.
c. WAP (Weight Average Price)
d. Gross Revenue

3. Aplikasi ini memberikan kemudahan dan keakurasian hasil yang lebih cepat dan tepat dibandingkan sistem sebelumnya yang ada di Asosiasi Daerah Penghasil Migas, karena dari hasil pengolahan data menggunakan software RapidMiner dan metode Algoritma C4.5 menghasilkan suatu akurasi yang cukup yaitu sebesar $54,05 \%$.

4. Metode Algoritma C45 dapat dipakai atau diterapkan untuk menentukan analisis lifting migas daerah penghasil migas.

\section{Saran}

Sebuah sistem yang dirancang tidak akan pernah sempurna karena sitem akan terus berkembang sesuai perkembangan zaman. Berdsarkan hal tersebut, maka terdapat beberapa saran yang harus dipertimbangkan, saran-saran tersebut adalah sebagai berikut :

1. Aplikasi ini masih harus dipertimbangkan kearah yang lebih sempurna dengan melakukan serangkaian uji coba dalam masa waktu tertentu sehingga dapat berguna bagi pihak Asosiasi Daerah Penghasil Migas.

2. Dilakukan perawatan dan perbaikan aplikasi apabila terjadi kerusakan secara berkala.

\section{DAFTAR PUSTAKA}

[1] Han, J., Kamber, M., \& Pei, J. (2011). Data Mining: Concepts and Techniques, 3rd.ed. Boston: Morgan Kaufmann

[2] Kusrini, \& Luthfi, E. T. (2009). Algoritma Data Mining. Yogyakarta: Andi Offset. 
[3] Bramer, M. (2007). Principles Of Data Mining. London: Springer.

[4] Vercellis, C. (2009). Data Mining and Optimization for Decision Making. Italy: WILEY.

[5] Nugroho, A. S., Witarto, A. B., \& Handoko, D. (2009, Desember 20). Retrieved Februari 22, 2013, from http://ilmukomputer.com: http://ilmukomputer.com
[6] Setiyo Cahyono. 2009. Pemrograman Database Menggunakan MySQL dan Java. Bandung : Informatika.

[7] Kadir, A. 2009.Dasar Perancangan \& Implementasi.Grassindo. Jakarta 